
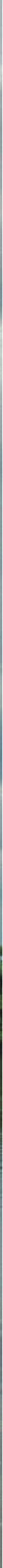



\title{
Ecoturismo, gubernamentalidad neoliberal y despojos en la Amazonia colombiana ${ }^{1}$
}

\author{
Iván Montenegro-Perini ${ }^{2}$ \\ Pontificia Universidad Javeriana, Colombia \\ ivane28@gmail.com \\ Recibido: 30 de julio de 2016 \\ Aceptado: 15 de febrero de 2017 \\ Disponible en línea: 14 de diciembre de 2017
}

1 Artículo de investigación que se deriva de los resultados parciales de dos proyectos de investigación: por un lado, de "Imperativos verdes y subjetividades ambientales campesinas en tres regiones de Colombia", financiado por la Vicerrectoría de Investigación de la Pontificia Universidad Javeriana (Proyecto 5433); y por otro, de "Estrategias para el fortalecimiento de las actividades organizativas y ecoturísticas de [una cooperativa ecoturística] en el Guaviare", financiado por el fondo Francisco Javier de la Rectoría de la Pontificia Universidad Javeriana.

2 Antropólogo y administrador de empresas, Pontificia Universidad Javeriana (Colombia). MA en Economía Política del medioambiente y la sociedad, Universidad de Manchester (UK). Estudiante de doctorado en Antropología, University of California Davis (EE.UU.). 


\title{
Ecoturismo, gubernamentalidad neoliberal y despojos en la Amazonia colombiana
}

\section{Resumen}

Este artículo analiza hasta qué punto los campesinos de una zona del departamento del Guaviare (Amazonia colombiana) fueron sujetados por los principios del ecoturismo neoliberal, y examina los efectos sociopolíticos asociados a la disposición de los conocimientos ambientalesempresariales en sus vidas. Exploro las adaptaciones y limites de la medioambientalidad neoliberal, en el marco del ecoturismo, y los efectos socioecológicos de sus tecnologías de gobierno sobre poblaciones campesinas. Me concentro particularmente en cómo estas tecnologías se adaptan a intereses de grupos particulares de la región, y en cómo, a través de diversos mecanismos i/legales, el ecoturismo se vuelve funcional a estrategias sofisticadas de despojo que los campesinos deben sortear. Por un lado, examino los despojos en nombre de la conservación a través de la culpabilización de los campesinos, y, por el otro, abordo la configuración de otras modalidades de despojo más sutiles que he llamado despojos político-ontológicos.

Palabras clave: ecoturismo; gubernamentalidad neoliberal; conservación; despojos; campesinos; Amazonia

\section{Ecotourism, Neoliberal Governmentality, and Dispossession in the Colombian Amazon}

\begin{abstract}
This paper analyzes the extent to which peasants in an area of Guaviare (Colombian Amazon) were subjected to neoliberal ecotourism principles, and examines the socio-political effects related to the incorporation of environmental-business knowledge in their lives. I explore the adaptations and limits of neoliberal environmentality within the framework of ecotourism and the socio-ecological effects of its government technologies on peasants populations. I focus particularly on how these technologies are tailored to the interests of particular groups in the region, and how, through various il/legal mechanisms, ecotourism becomes functional to sophisticated dispossession strategies that peasants must face. On the one hand, I examine dispossessions in the name of conservation by blaming in peasants, and on the other hand, I approach the configuration of other subtler forms of dispossession that I have called politico-ontological dispossessions.
\end{abstract}

Keywords: ecotourism; neoliberal governmentality; conservation; dispossessions; peasants; Amazonia

\section{Ecoturismo, governamentalidade neoliberal e espoliação na Amazônia colombiana}

\section{Resumo}

Este artigo analisa até que ponto os camponeses de uma área do departamento de Guaviare (Amazônia colombiana) foram sujeitos pelos princípios do ecoturismo neoliberal, e examina os efeitos sócio-políticos associados à disposição dos conhecimentos ambientais-empresariais nas suas vidas. Exploro as adaptações e limites da meioambientalidade neoliberal, no quadro do ecoturismo, e os efeitos sócio ecológicos de suas tecnologias de governo sobre populações camponesas. Foco-me particularmente em como é que tais tecnologias adaptamse a interesses de grupos particulares da região, e como, através de diversos mecanismos i/legais, o ecoturismo torna-se funcional a estratégias sofisticadas de espoliação com que os camponeses devem lidar. Por um lado, examino as espoliações em nome da conservação através da inculpação dos camponeses, e, por outro, abordo a configuração de outras modalidades de espoliação mais súteis que chamei de espoliação político-ontológica.

Palavras-chave: ecoturismo; governamentalidade neoliberal; conservação; espoliação; camponeses; Amazônia 


\section{Introducción}

El ecoturismo se ha convertido en el sector de la industria del turismo que más rápido ha crecido en las últimas décadas y en una actividad central en las agendas políticas de muchos países del sur-global para alcanzar el desarrollo sostenible (West y Carrier, 2004). No obstante, las ciencias sociales han demostrado con trabajos empíricos que el ecoturismo es un medio en el que la naturaleza ${ }^{3}$ se "neoliberaliza", al ponerla en un régimen de producción que la convierte en un campo particularmente deseable para generar beneficios económicos, y que a su vez configura procesos sofisticados de despojo que contribuyen a que el sistema capitalista solvente sus crisis de sobreacumulación y de devaluación de capital en nombre de la conservación (West y Carrier, 2004; Brockington et al., 2008; Duffy, 2008; West, 2008).

En el Guaviare (Amazonia colombiana), el ecoturismo se ha convertido en una actividad objetiva para legalizar y medioambientalizar a los campesinos-cocaleros, visibilizar la diversidad cultural y natural de la región, proteger el medioambiente, establecer un mayor control territorial e insertar al departamento en la economía colombiana. Los campesinos de la zona han sido objeto de regulación politica por parte de distintas instituciones que han buscado transformar sus prácticas, consideradas ilegales (coca) y depredadoras del medioambiente, para mejorar sus condiciones de vida y convertirlos en sujetos emprendedores-ambientales en el marco del ecoturismo neoliberal. Como lo mostraré en este artículo, las politicas ambientales y las intervenciones sobre los campesinos para poner en funcionamiento el ecoturismo neoliberal operaron produciendo milieus que les permitiesen a los campesinos establecer sus propias iniciativas ecoturísticas bajo las racionalidades de mercado (Foucault, 2007; Li, 2007; Rose, 2007). Las tecnologías de gobierno buscaban regular a los campesinos "a distancia", animándoles a convertirse en "emprendedores de sí mismos" (Foucault, 2007);

\footnotetext{
En este artículo hago una distinción entre Naturaleza y naturalezas. La primera tiene que ver con la concepción moderna de que la Naturaleza existe de antemano, que es algo externo a nosotros que espera ser interpretado; la segunda se refiere a las naturalezas como procesos de constante e inacabada reproducción, que no pueden pensarse por fuera de las dinámicas políticas, sociales y económicas de determinados contextos sociohistóricos. Con naturalezas hago referencia a las múltiples y heterogéneas relaciones socioecológicas existentes y posibles.
} 
es decir, llevando a cabo acciones autorreguladoras dentro de las lógicas de la conservación neoliberal. En ese sentido, el concepto de gubernamentalidad (Foucault, 1999), matizado en las nociones de eco-gubernamentalidad (Ulloa, 2005) y medioambientalidad (Agrawal, 2005), es central para entender las formas de gobierno de la Naturaleza y la formación de racionalidades y tecnologías de gobierno para la acumulación de capital (Rose, 1996; Biersack, 2006; Li, 2007). ${ }^{4}$ En este artículo utilizaré el concepto de medioambientalidad neoliberal para examinar el rol de las racionalidades y tecnologías de gobierno en la producción de campesinos emprendedores-ambientales, en el contexto del ecoturismo neoliberal, tomando en consideración "los bloques conceptuales de poder, conocimientos, instituciones y subjetividades" (Agrawal, 2005, p. 8).

Ahora bien, los resultados de los procesos de gubernamentalización de la Naturaleza y de los sujetos no están garantizados de acuerdo al plan que se propone (Li, 2007). Las politicas ambientales se adaptan y articulan de formas disimiles según las circunstancias sociohistóricas específicas (Shore, 2010), y es ahí en donde se presentan escenarios de tensiones y conflictos socioecológicos entre los diferentes actores, incluidos los no-humanos (Latour, 1993), que producen nuevas subjetividades, naturalezas y procesos de despojo (Li, 2007; Cepek, 2011; Montenegro-Perini, 2016). El caso del ecoturismo en el Guaviare no es ajeno a las constantes adaptaciones y reconfiguraciones de los programas gubernamentales que surgen a través de la interacción entre múltiples redes de actores, voluntades e intereses. ${ }^{5}$ Desde esa perspectiva, me interesa analizar hasta qué punto los campesinos de la zona norte

4 Foucault (1999) señala que la gubernamentalidad tiende hacia la preeminencia de un tipo de poder que él llama gobierno, que está por encima del poder soberano y disciplinario. El gobierno puede ser definido sucintamente como la conducta de la conducta, como el intento por transformar la conducta humana a través de medios calculados. A diferencia de la disciplina, que busca reformar grupos a través de la supervisión detallada en espacios cerrados como la prisión, el gobierno se enfoca en el bienestar de las poblaciones a través del mejoramiento de sus condiciones, el incremento de su riqueza, longevidad, salud, etc., por medio de acciones autorreguladoras ( $\mathrm{Li}, 2007)$.

5 Li (2007) señala que la gubernamentalidad tiene límites que se concretan a través de los tipos de población hacia los que las políticas son dirigidas y los tipos de conocimiento que se implementan. Primero, ni los actores que son intervenidos, ni los funcionarios, son pasivos ante el contenido de las políticas; por el contrario, tienen poder de agenciamiento, el cual está interpelado por las circunstancias sociohistóricas en las que viven estos sujetos y que influye en el modo en que se aplican las políticas. Segundo, los beneficios de las políticas no están garantizados, entre otras cosas, porque los diagnósticos de los problemas no son completos: "las intervenciones frecuentemente producen efectos que son contradictorios, incluso perversos" (Li, 2007, p. 18). 
del departamento del Guaviare, Amazonia colombiana, fueron sujetados por los principios del ecoturismo neoliberal, y examinar los efectos sociopolíticos asociados a la disposición de los conocimientos ambientales-empresariales en sus vidas. Me concentraré en cómo las politicas y programas en ecoturismo se adaptaron a intereses de grupos particulares de la región, y en cómo, a través de diversos mecanismos i/legales, el ecoturismo se volvió funcional a estrategias sofisticadas de despojo que los campesinos debieron sortear. Mostraré que la responsabilidad sobre la desposesión recayó sobre algunos campesinos que habían tratado de trabajar en el ecoturismo, resignificando su sentido en sus propios términos. Este proceso de agenciamiento llevó a que fuesen representados culturalmente por distintos actores regionales como sujetos incapaces de gestionar este tipo de iniciativas, aun después de haber sido capacitados con el conocimiento apropiado, y, por ende, justificó la idea de que debían salir de ese mercado para darles paso a emprendedores que sí pudiesen hacerlo. Las políticas ambientales se articularon a voluntades e intereses particulares, haciendo que su aplicación se desplegara selectivamente sobre aquellos campesinos que fueron incapaces de responder a las lógicas de privatización y emprendimiento, y que configurara violentos 6 intentos de despojo en nombre de la conservación.

Por otro lado, este artículo también contribuirá a la comprensión del despojo más allá de su concepción como un fenómeno que causa la pérdida de la tierra y los medios de producción (Marx, 1990) o desposesión de algún objeto material a través de mecanismos coercitivos, para comprenderlo en sus múltiples dimensiones simbólico-materiales y en los efectos que genera en la vida de quienes son despojados (Arias y Caicedo, 2016, 2017). Recientes trabajos han abordado el despojo como fenómeno de suspensión de las relaciones socioecológicas y modos de vida de poblaciones disímiles (Bosa, 2016; Montenegro-Perini, 2016; Ojeda, 2016; Rocheleau, 2016); como transformador de los significados de la tierra (Morris, 2017); como configurador de las relaciones de raza, género y clase (Federici,

6 Es importante señalar que las violencias que entraña el despojo son diversas; desde la acción coercitiva que se ejerce sobre humanos y no-humanos, hasta acciones que pueden pasar inadvertidas al operar mediante el consentimiento de sus víctimas (Ojeda, 2016; Arias y Caicedo, 2017). 
2010; Meertens, 2016; Caicedo, 2017; Calle, 2017; Camacho, 2017; León, 2017), y como productor de nuevas subjetividades (Butler y Athanasiou, 2013). El ecoturismo en el Guaviare además de configurar procesos de despojo a través de la culpabilización de los campesinos, también trata de despojar las complejas relaciones socioecológicas que los campesinos establecen con su entorno y los no-humanos para abrir espacios de acumulación de capital. En efecto, lo que se despoja no es solo la tierra sino también, como lo señala Ojeda, "los anhelos y los planes para el futuro: lo que los hijos no van a conocer, lo que ya no se puede hacer, adonde ya no se puede volver, lo que ya no se va a ser" (2016, p. 34). No obstante, el despojo del entramado de las relaciones entre humanos y no-humanos no solo implica la restricción al acceso a los recursos, la pérdida de autonomía (Ojeda, 2016) y la capacidad de reproducir la vida (Rocheleau, 2016), sino el intento de las tecnologías de gobierno neoliberales de cooptar la posibilidad de la emergencia de lo político, ${ }^{7}$ a través de la invisibilización de la multiplicidad de mundos que podrían contribuir a la configuración de alternativas a las coordenadas sociometabólicas actuales (capitalismo moderno). Por lo tanto, el despojo del que hablo aquí es político-ontológico. ${ }^{8}$ Aunque esta categoría está todavía en construcción y merece mayor atención, hacer una primera aproximación a ella puede mostrarnos algunos de los mecanismos de cómo la producción de la Naturaleza y de los sujetos emprendedores-ambientales en el marco del ecoturismo neoliberal busca invisibilizar y desestabilizar las relaciones socioecológicas que mantienen los campesinos con la selva, para abrir nuevos espacios de acumulación de capital, y, por ende, negar otros mundos o formaciones ontológicas ${ }^{9}$ por medio de formas muy sutiles que operan a través del consentimiento de los campesinos (Arias y Caicedo, 2017).

Aquí me refiero a lo político como el escenario de tensiones, conflictos y antagonismos, y a las políticas como las técnicas de gestión de poblaciones y recursos (Swyngedouw, 2011).

8 Marisol de la Cadena (2010) plantea, a través de su estudio de las comunidades indígenas andinas, que la visibilización de los mundos de estas poblaciones permitiría la reconfiguración de lo político a través de la pluralización ontológica de la política. Aquí no se trata de la pluralidad ideológica, de género o racial (Arias y Caicedo, 2017), ni tampoco de la incorporación de las diferencias en un marco multicultural mejor, así como tampoco de una estrategia de ganar la hegemonía. Se trata más bien de la posibilidad de comprender la emergencia de lo político a través de las disputas y conflictos, no dentro de un mundo singular, sino a través de las relaciones de tensión entre mundos disímiles (De La Cadena, 2010). Los despojos político-ontológicos buscan por lo tanto negar e invisibilizar estos otros mundos posibles.

9 Ahora bien, los intentos de despojo político-ontológicos no implican el fin de la agencia de los sujetos, ya que estos no son completamente efectivos. Como lo señalan Butler y Athanasiou (2013), el despojo produce nuevas subjetividades 
Para comprender los grados de sujeción de los campesinos a las racionalidades del ecoturismo, así como la configuración de los distintos procesos de despojo en el Guaviare, usé el método etnográfico. La etnografía me permitió analizar los efectos que las políticas ambientales producían, las relaciones que configuraron y las racionalidades que las sustentaban, así como también examinar la agencia de los beneficiarios y funcionarios en su aplicación (Shore, 2010). Las estrategias de investigación usadas fueron: 1) conversaciones informales con campesinos y funcionarios públicos; 2) entrevistas semiestructuradas; y 3) análisis antropológico de la política pública ambiental a través de la revisión documental.

El artículo se estructura de la siguiente forma: primero, examino el nacimiento del ecoturismo en el Guaviare y sus tecnologías de gobierno. Después, analizo la producción de subjetividades emprendedoras-ambientales a través de los procesos de capacitación del Programa de Familias Guardabosques, y cómo estas tecnologías de gobierno configuraron intentos de despojo en nombre de la conservación y el emprendimiento. Finalmente, abordo los procesos de despojo político-ontológicos como tecnologías sofisticadas del capitalismo moderno para abrir espacios de acumulación de capital, y sus efectos en la vida de los campesinos del noroccidente amazónico.

\section{El ecoturismo: racionalidades y tecnologias de gobierno}

Los programas y politicas en la Amazonia colombiana, soportados por criterios científicos, han creado una serie de enunciados sobre este territorio y sobre las prácticas de los campesinos que lo habitan. Estas representaciones han justificado diferentes estrategias de intervención estatal. Particularmente, se destaca cómo la

que no responden fielmente a las racionalidades de gobierno, sino a los ensambles ontológicos entre las diferentes coordenadas socioecológicas que se disputan (Montenegro-Perini, 2016). En estos ensamblajes se forjan paisajes de resistencia, vida y esperanza (Ojeda, 2016). En este artículo no abordaré la reconfiguración de las subjetividades y naturalezas campesinas a través de los ensamblajes ontológicos, pero sí quiero dejar claro que los despojos no son solo destructivos, sino también productores de nuevas agencias que pueden generar resistencias y posiciones políticas renovadas de los campesinos que participan del ecoturismo. 
Amazonia se ha producido en tanto espacio en condiciones de salvajismo, de ilegalidad y, recientemente, con los discursos ambientales, como zona de vocación forestal que debe ser conservada. Los campesinos y habitantes no indígenas han sido producidos como sujetos inmersos en condiciones de ilegalidad por ser productores de coca, depredadores del medioambiente y auxiliares de la guerri1la. Bajo estas representaciones se han creado politicas de intervención sobre ellos que además se articulan a una normatividad ambiental que rige estos territorios. ${ }^{10}$

En la década del 2000, varias instituciones llegaron a la conclusión de que el ecoturismo sería la actividad económica que permitiría transformar las dinámicas de ilegalidad de los campesinos asociadas a la coca, generar réditos económicos a poblaciones empobrecidas y responder a la normatividad ambiental de la región. En el 2005, el Instituto Sinchi desarrolló un proyecto titulado "Capacitación sobre servicios ambientales con base en el trabajo concertado de planificación, valoración y diseño de una experiencia piloto en ecoturismo, para los departamentos del norte amazónico colombiano". En el proyecto participaron diversas instituciones y organizaciones, tales como el Parque Natural Nacional del Chiribiquete, la Secretaría de Cultura y Turismo, la Corporación para el Desarrollo Sostenible del Norte y Oriente Amazónico (CDA), entre otras. A partir de este trabajo conjunto, se sentaron las bases conceptuales y metodológicas sobre las formas de gestión de iniciativas de ecoturismo en el departamento. ${ }^{11}$ Con el ecoturismo sería posible convertir a los ecosistemas naturales en fuentes de valor y atracción, contribuir a la protección de los ecosistemas y la vida silvestre a través de la conservación, y capacitar a las comunidades de base para que participaran en la toma de decisiones y operación de esta actividad (Sinchi, 2006).

${ }^{10}$ El departamento del Guaviare está regido por diferentes figuras normativas ambientales; hace parte de la Zona de Reserva Forestal de la Amazonia (Ley $2^{\mathrm{a}}$ de 1959), y el territorio en donde se realiza el análisis de este trabajo pertenece al Distrito de Manejo Integrado Ariari-Guayabero, constituyente del Área de Manejo Especial de La Macarena (AMEM). El trabajo de Vergara (2016) en la región analiza las tensiones y conflictos que generan los instrumentos cartográficos y las figuras normativas para el ordenamiento territorial sobre las vidas cotidianas de las poblaciones que habitan este territorio.

11 No se puede soslayar que el ecoturismo como una actividad socio-económico-ambiental se estructura bajo los parámetros de la Ley 99 de 1993 (nivel nacional) como un elemento constituyente y promotor del desarrollo sostenible. 
Posteriormente, el plan de turismo del departamento del Guaviare "Primer Destino Turístico Sostenible de Colombia 20082020" concretaría legalmente estas iniciativas y proyectos, resaltando la diversidad cultural y natural del Guaviare. La interacción de la cultura indígena, los colonos de distintos lugares del país y la riqueza natural se convertirían en aspectos centrales en la construcción de identidad regional desde las lógicas estatales. Eslóganes tales como "paraíso ecológico", "Guaviare diferente a todo", "una aventura por descubrir"; las imágenes de los nukak reflejando su armónica convivencia con la selva, micos (monos), jaguares, ríos y toninas (delfines rosados); y el festival Yurupari de Oro, en donde se conjugan la cultura indígena, colona y la diversidad natural, se convertirian en elementos a través de los cuales se desarrollarian las políticas de ecoturismo en la región. Al Guaviare se le daría un capital simbólico (Bourdieu, 1994) al producirlo como un espacio único y auténtico cargado de imágenes idílicas de indígenas intocados y naturalezas prístinas, con el objetivo de generar rentas de monopolio (Harvey, 2001).

Bajo esta imagen, los campesinos cocaleros debían ser normalizados y transformados en sujetos que no solamente respondieran a las imágenes idílicas del Guaviare "paraíso ecológico", sino que también fueran capaces de emprender prácticas autorreguladas dentro de las lógicas del ecoturismo. ${ }^{12}$ De no hacerlo, los campesinos serían leídos como destructores de la naturaleza y sujetos ilegales, lo que les limitaría el acceso a los recursos naturales e incluso resultaría en su criminalización, despojo y persecución (Del Cairo y Montenegro-Perini, 2015; Bocarejo y Ojeda, 2016). En otras regiones de Colombia, por ejemplo, las prácticas de conservación, incluido el ecoturismo, han desplegado estrategias de borradura de las comunidades campesinas a través de su criminalización, despojo y amenazas de muerte por no ser los tipos de sujeto que pueden convivir con la Naturaleza, como sí son considerados los indígenas (Ojeda, 2012a; González, 2014; Bocarejo y Ojeda, 2016). ${ }^{13}$ A

${ }^{12}$ Hoy en día, en el contexto del postconflicto, el ecoturismo ha tomado mayor fuerza al convertirse en una de las actividades de mayor interés para introducir a las regiones más azotadas por la violencia en la economía colombiana.

${ }^{13}$ El Proyecto Radargramétrico del Amazonas (Proradam) fue el primer proyecto científico en la región que reprodujo la oposición binaria entre campesinos e indígenas, asumiendo con criterios científicos que el primero veía la Naturaleza 
diferencia de estos casos, el ecoturismo en el Guaviare se convertiría en una tecnología de gobierno para la regulación y transformación de los campesinos ilegales y depredadores de la Naturaleza en campesinos emprendedores-ambientales, lo que les permitiría responder a los requerimientos de conservación y desarrollo. Así, el ecoturismo promovería un tipo particular de sujetos y naturalezas que permitiesen la acumulación de capital, la legalización de los campesinos y la conservación ambiental a través del fortalecimiento comunitario, ${ }^{14}$ así como también la mercantilización de la naturaleza y la cultura, características centrales en las formas de gobierno neoliberales (Rose, 1996; Fletcher, 2010; Castree, 2011; Gershon, 2011).

Para transformar esas condiciones anormales de los campesinos y sintonizarlos con la representación del Guaviare como espacio de diversidad cultural y natural, el ecoturismo fue articulado a los programas de Desarrollo Alternativo (PDA) que se venían implementado desde hace más de una década atrás en el Guaviare. E1 PDA se había constituido en uno de los dos pilares de la guerra contra las drogas en la década de $1990,{ }^{15}$ a través del desarrollo rural y ambiental. En la década del 2000, el gobierno de Álvaro Uribe (2002-2010) redefinió el programa, convirtiéndolo en un componente central de la Politica de Seguridad Democrática;una política de securitization $^{16}$ que se alzaba en concordancia con la lucha contra las drogas y la guerra contra el terror, y que se establecía como una respuesta urgente de restauración del orden y el dominio de la ley en territorio colombiano, para devolverles a sus habitantes la posibilidad de viajar y desplazarse por el territorio (Ojeda, 2012a). El objetivo era recuperar los territorios que estaban bajo el poder de

como un objeto que debía ser transformado, mientras que el segundo tenía patrones culturales que convergían armoniosamente con el ecosistema amazónico. A nivel nacional, la producción de la diferencia a través del discurso multicultural ha convergido con los discursos de conservación, oponiendo los modos de vida de los campesinos a la protección del medioambiente (Ulloa, 2005; Cárdenas, 2012).

14 El Plan Nacional de Desarrollo "Hacia un Estado Comunitario" (2003), del cual el estudio del Sinchi basó parte de su orientación investigativa, señalaba que debido a que Colombia poseía una de las mayores concentraciones de especies por unidad de área en el mundo, se convertía en un destino en el que el ecoturismo y otros servicios ambientales jugaban un rol fundamental como generadores de ingresos y empleo "verde" (DNP, 2003).

15 La lucha contra la producción de drogas ilícitas se ha caracterizado por dos tipos de componentes: uno represivo, que opera a través de la erradicación forzosa, a través, principalmente, de fumigaciones con glifosato, y otro promotor, que sustituye el cultivo de uso ilícito mediante estímulos dirigidos para remplazarlo con otros de tipo legal (Zorro, 2011).

16 El término securization hace referencia a un proyecto cultural y político de hipervigilancia y exclusión de espacios y sujetos a través de la movilización del miedo y la militarización (Ojeda, 2013). 
la guerrilla, el narcotráfico y el "terrorismo", a través de la acción combinada de la militarización y el turismo (Ojeda, 2012b). En el caso del Guaviare, esta política tuvo efecto en la finalización de la carretera Bogotá-Villavicencio-San José del Guaviare, en la militarización del departamento y en la creación de un grupo especial de policias para la protección y fomento del turismo en la región.

Como parte del Desarrollo Alternativo, surgió el Programa de Familias Guardabosques (PFGB) que también buscaba frenar el avance de los cultivos de uso ilícito y proteger las áreas ambientalmente estratégicas a través de mecanismos de gobierno de empoderamiento de las comunidades. El PFGB proporcionaba apoyo en:

asistencia técnica para fortalecer el trabajo comunitario, fomentar capacidades gerenciales y de mercadeo dentro de la legalidad, así como la promoción de una conciencia ambiental, planes administrativos racionales, el uso de abonos orgánicos, entre otros. El objetivo general era empoderar a las familias para que se convirtieran en participantes activos, a nivel local y regional, de los procesos de desarrollo sociales y económicos. (AcciónSocial, UNODC, 2007, p. 18)

El PFGB tenía diferentes componentes para el desarrollo sostenible, entre los cuales estaba la organización de "posadas turísticas". Esta iniciativa propendía por la transformación de las condiciones de los campesinos como cultivadores de coca, para convertirlos en anfitriones turísticos, guardabosques y sujetos emprendedores-ambientales. Ellos recibirian capacitaciones como proveedores turisticos, asistencia técnica en temas ambientales y empresariales y mejoramiento de la infraestructura, siempre y cuando mantuvieran su territorio libre de coca y se dedicaran a actividades sostenibles como el ecoturismo y la agricultura a pequeña escala (Ortiz, 2016). Estos mecanismos de gobierno respondieron al funcionamiento del gobierno neoliberal al intervenir no directamente sobre los individuos, sino sobre las condiciones en las que se desenvolvían, creando unas reglas de juego específicas. El neoliberalismo no se enfoca en conducir la conducta de los individuos 
directamente, sino que crea un milieu caracterizado por configurar dinámicas de riesgo, en el cual los individuos emprenden acciones autorreguladoras (Foucault, 2007; Li, 2007; Rose, 2007; Fletcher, 2010). La función del estado es incentivar a los individuos para que se conviertan en jugadores dentro de las dinámicas de mercado; a quienes no tengan los capitales para hacerlo se les entrega un "capital semilla" ${ }^{17}$ que les permita empezar a hacerlo. Es un gobierno sobre la intimidad en el cual el individuo se convierte en el empresario de sí mismo (Foucault, 2007), y en donde él y las comunidades a pequeña escala son el lugar de la subjetividad neoliberal (Rose, 2007; Fletcher, 2010; Castree, 2011; Gershon, 2011). En el caso concreto del PFGB, la idea era convertir a los campesinos en emprendedores ambientales a través de un "capital semilla" que les permitiria autogestionarse en comunidad y actuar emprendedoramente en el campo del ecoturismo. Esto llevaría a la legalización y medioambientalización de los campesinos para que sus prácticas se sintonizaran con la legislación ambiental y con las imágenes de autenticidad que demandaba el ecoturismo en el departamento para el buen funcionamiento del mercado.

\section{Subjetividades emprendedoras-ambientales y culpabilización de los campesinos}

La generación de entornos de riesgo e incertidumbre es parte integral de la racionalidad neoliberal y del capitalismo (Swyngedouw, 2010), ya que estimula la competitividad y el autogobierno. Del mismo modo, el predicamento ecológico está saturado por temores milenarios que plantean un escenario apocalíptico en el cual nuestras vidas están en riesgo de extinción, lo que hace del miedo un nodo crucial a través del que la narrativa medioambiental es tejida (Swyngedouw, 2010). En el Guaviare, el Plan de Manejo de la serranía de La Lindosa (2005), desarrollado por la Corporación Ambiental Regional (CDA), se convirtió en el hito fundacional de

17 El capital semilla puede ser comprendido como una especie de subsidio temporal que se les otorga a los individuos para capitalizarse y comenzar a jugar dentro de un campo de acción determinado, en este caso, el ecoturismo. Ahora, este capital no es solamente económico, sino también cultural y social, tal y como lo entiende Bourdieu. 
riesgo asociado con la materialización de la normatividad ambiental. ${ }^{18}$ El Plan tenía como objetivo mitigar el impacto antrópico sobre la serranía, a partir del establecimiento de una zona campesina de manejo especial y producción sostenible (Del Cairo, MontenegroPerini y Vélez, 2014; Del Cairo y Montenegro-Perini, 2015). Muchos campesinos vieron en esta iniciativa un riesgo inminente sobre la tenencia de la tierra, ya que sus medios de producción eran considerados no aptos para el medioambiente. Como resultado, muchos de ellos se organizaron no solo para negociar el Plan de Manejo, ${ }^{19}$ sino también para transformar definitivamente sus condiciones de vida, que justificaban la representación que las instituciones y funcionarios hacían de ellos como depredadores e ilegales. Esto les permitiria, entre otras cosas, sortear los riesgos asociados a la pérdida de tierras:

Después de lo que pasó con la CDA y ese Plan de Manejo yo pensaba que era necesario principiar una transformación de las cosas porque si no perderíamos nuestras casitas. [...] En esa época yo trabajaba con la coca y cuando mi hijo creció me dijo que quería empezar a trabajar conmigo. Claro, yo me preocupé. Entonces decidí cambiar mi actividad de ingresos para evitar que él cayera en malas manos; eso había mucho paramilitar y el gobierno jodía bastante también. [...] En esa época salió ese PFGB y algunos de nosotros buscamos la posibilidad de trabajar con ellos.

(Diario de campo, 2013)

Fue así como varios campesinos vieron en el PFGB una alternativa para sortear los riesgos socioambientales antes descritos y transformar su imagen subvalorada. Simultáneamente, conformaron iniciativas ecoturísticas en forma de cooperativas, las cuales demostraron, entre otras cosas, que los campesinos en ningún momento fueron sujetos pasivos frente a estas nuevas dinámicas socioambientales que se empezaban a vivir en la región.

${ }^{18}$ Si bien la normatividad ambiental existía desde muchos años atrás, el primer esfuerzo de alcance transformativo sobre el territorio fue este Plan.

${ }^{19}$ Los campesinos lograron frenar el Plan y desarrollar junto con Cindap un Plan alternativo de Comanejo. En ese proceso se conformó la Corporación para la Conservación y el Desarrollo Sostenible de la Serranía de La Lindosa (Corpolindosa), una asociación campesina. 
Los campesinos organizados en cooperativas recibieron diferentes capacitaciones para que pudieran autorregularse dentro del campo del ecoturismo neoliberal y se convirtiesen así en emprendedores ambientales. También fueron objeto calculable a través de una gran variedad de informaciones, normas, representaciones e investigaciones. Como lo diría Rose (1996), la comunidad fue gubernamentalizada. La idea era convertir las cooperativas en empresas asociativas de carácter privado, a través de la empresarialización y medioambientalización de sus miembros (Castree, 2011). ${ }^{20}$ Esto les permitiría a los campesinos comenzar a cobrar por los servicios prestados en materia de ecoturismo, al vender servicios ambientales basados en el ofrecimiento de una experiencia cercana a la Naturaleza prístina, a visitantes ansiosos por vivir y consumir de ella. Las capacitaciones que desarrollaron los funcionarios del PFGB se basaron en dos temas generales: 1) conocimiento de conservación medioambiental; y 2) conocimiento empresarial, organizacional y contable.

Agrawal (2005) señala que existe un tipo particular de sujetos para quienes el medioambiente es una categoría conceptual que organiza su pensamiento y, por ende, sus formas de actuar. Estos individuos, a quienes llama "sujetos ambientales" están "sujetados" por una forma específica de pensamiento que responde a los principios de conservación y cuidado del medioambiente, pero también, agrego yo, a las lógicas del capital. A medida que ellos incorporan estas lógicas en sus prácticas cotidianas se convierten en parte de sus formas de ver el mundo. En el caso de los campesinos, sin embargo, los efectos de sujeción fueron diversos y complejos, ya que ellos resignificaron el conocimiento del ecoturismo desde sus propias formas de existencia (ontologías) y relacionamientos socioecológicos, lo que demuestra los límites (Li, 2007) de la medioambientalidad neoliberal. En este artículo no abordo las reconfiguraciones de las relaciones simbólico-materiales de los campesinos con la selva y el estado (ver Montenegro-Perini, 2016), sino hasta qué punto los campesinos

${ }^{20}$ Los trabajos de Ojeda (2012a) y González (2014) en el Parque Tayrona; de Bocarejo (2012) en La Sierra Nevada de Santa Marta, y de Bocarejo y Ojeda (2016) en la Costa Caribe colombiana muestran casos similares de empresarialización y medioambientalización de sujetos a través de la asociatividad, así como también los efectos socioecológicos y las adaptaciones particulares de estos mecanismos de gobierno en diferentes contextos. 
fueron sujetados por los principios de la conservación neoliberal, y los efectos de ello en la configuración de procesos de despojo.

Para rastrear esos modos de sujeción es necesario que me remita a los grados de participación generalizada de los campesinos en prácticas regulatorias específicas. Los líderes de algunas de las cooperativas tuvieron un papel representativo en la ejecución ecológica y transformativa de las actitudes de los campesinos sobre el medioambiente y, en este caso, del ecoturismo. Inicialmente, en una de las cooperativas, muchos campesinos desconfiaban de la viabilidad del ecoturismo en una región que históricamente había estado sumida en el conflicto armado, pero gracias a la participación conjunta del líder y de otras instituciones se llevaron a cabo capacitaciones y viajes a otras regiones en donde se habian desarrollado iniciativas similares, para que los campesinos cambiaran su punto de vista hacia esta actividad:

Los de Parques [Naturales] nos empezaron a ayudar, a darnos ideas, charlas, y organizaron con los de la Secretaría de Cultura y Turismo unas salidas a Santa Marta y a las Islas del Rosario. Eso fue muy bueno, porque nos dimos cuenta de muchas cosas buenas que teníamos acá. Imagínese que en las islas no tenían agua dulce y así les iba bien. Nosotros acá tenemos agua por todos lados. Entonces si les iba bien a ellos, ¿por qué no nos iría bien a nosotros? (Diario de campo, 2013)

Lo resultados de estas capacitaciones y viajes fueron variados. Desde aquellos que comenzaron a monitorear y sancionar las prácticas de sus vecinos que no eran acordes con las "formas correctas de actuar", pasando por aquellos que utilizaban estratégicamente el discurso ambiental institucional para sortear los riesgos de despojo de tierras, hasta quienes no vieron en el ecoturismo ningún beneficio.

Los campesinos que comenzaron a sancionar y monitorear a sus vecinos fueron aquellos que apropiaron significativamente el 
discurso de conservación y ecoturismo en sus prácticas cotidianas. Una campesina señalaba:

El señor de esa casa ha empezado a conservar desde que vinieron los de guardabosques. Antes estaba acostumbrado a tumbar y a quemar, aún todavía lo hace, pero le ha mermado también porque nosotros le decimos y recordamos las consecuencias de eso. Este año ese vecino no ha quemado ni tumbado. Para qué, pero el viejo también se ha concientizado. (Entrevista a campesina, 2013, julio 18)

Además, algunos campesinos no solo monitoreaban y sancionaban a sus vecinos, sino que educaban a sus hijos para evitar que desarrollaran prácticas nocivas para la Naturaleza. La idea no era solo abordar el problema cuando ya se había materializado, sino también anticiparse a él a partir de la enseñanza sobre los modos "correctos" de hacer las cosas:

Yo lo que quiero por ejemplo es orientar a mi hija para que conservemos, que si le gusta y pudiera estudiar algo que tenga que ver con el medioambiente que lo pudiera trabajar en el Guaviare. De hecho, nosotros, sobre todo los más jóvenes, estamos proyectando la zona en donde vivimos como un lugar para la conservación, como un refugio de los animales que por allá están explotando, matando, acabando. Si conservamos, tendremos mayores posibilidades de vivir mejor. (Entrevista a campesino, 2013, julio 31)

Este testimonio demuestra también que los campesinos empezaban a interesarse en la conservación y el ecoturismo, porque les permitiría acoplarse a los requerimientos ambientales, crear nuevas oportunidades de vida, transformar las representaciones negativas que hacian ciertas racionalidades sobre ellos - como depredadores del medioambiente e ilegales-y evitar los riegos de ser desalojados de sus tierras. Un campesino señalaba: 
La naturaleza sirve para conseguir algo de dinero para poder comer y sostener a la familia, además, si no la conservamos, ¿qué les vamos a dejar a nuestros hijos? [...] A nosotros nos interesa vivir tranquilos. No queremos volver a vivir con lo de la coca, porque eso es un riesgo para nosotros y nuestros hijos; queremos que nuestros hijos puedan vivir mejor que nosotros sin que se tengan que meter con los unos (guerrilla) o con los otros (paramilitares); queremos que no nos quiten nuestras tierras. Si conservamos las cosas van a estar mejor. (Diario de campo, 2013)

Otros campesinos se vincularon parcialmente a las iniciativas ecoturísticas, y a los discursos asociados a ellas, para sortear los riesgos de perder sus tierras. No obstante, no acogieron realmente los conocimientos que las instituciones habian transmitido. Ellos modulaban un discurso ambiental que los legitimara frente a las instituciones como campesinos ecológicos, para sortear los riesgos de desposesión, pero no ponían en práctica el conocimiento adquirido. Esto fue rastreable a través de la comparación de las respuestas que los campesinos dieron a las entrevistas con aquellas que surgieron cuando la relación investigador-investigado se había fortalecido a través de lazos de confianza. Un campesino señalaba en una entrevista:

Las instituciones nos enseñaron muchas cosas relacionadas con la conservación. Es que la naturaleza hay que cuidarla. Nosotros hemos estado reforestando todo aquello que utilizábamos para los cultivos. Lo que tenemos ahora en cultivo, eso lo estamos rotando, les damos por ahí tres hectáreas y lo vamos rotando todos los años. Pero de resto lo pensamos dejar quieto para potenciarlo para el visitante para que se sienta mejor. (Entrevista a campesino, 2013, julio 13)

El mismo campesino meses después matizaba: "Es que la relación con las instituciones es complicada. Ellos quieren sacar partido de todo lo nuestro. El ecoturismo que ellos querian aplicar aquí era para beneficiarse ellos. Yo mantengo mis rastrojitos, pero 
si tengo que tumbar un palo para hacer la comida, pues lo hago" (Diario de campo, 2013).

La conservación del medioambiente se resignificó contextualmente bajo los intereses de los campesinos. La apropiación de ese discurso de conservación para la implementación del ecoturismo no significa que estos hubiesen tenido un rol pasivo frente a él y a las instituciones que lo promovian, sino que, por el contrario, su apropiación estuvo sujeta a transformaciones y adaptaciones que los campesinos generaron de acuerdo a su realidad e intereses (Montenegro-Perini, 2014, 2016; Vélez, 2015).

Por su parte, las capacitaciones empresariales a través de los talleres de emprendimiento, hotelería, contabilidad básica, etc., no tuvieron resultados efectivos en los modos de vida de muchos de los campesinos de una de las cooperativas ecoturísticas de la región. De manera similar a los casos del Parque Tayrona (Ojeda, 2012a; González, 2014) y la Sierra Nevada de Santa Marta (Bocarejo, 2012), la empresarialización de los campesinos tuvo varios problemas que fueron atribuidos principalmente a sus condiciones culturales, lejanas al funcionamiento efectivo del mercado. Un funcionario explicaba el asunto así:

El problema es que son factores culturales los que los mueven a ellos y nos mueven a nosotros. [...] Ellos siempre han estado acostumbrados a que el almuerzo lo sirven así, y no entienden que hay que ponerle un trapito aqui, que hay que lavar la loza bien. Para ellos no es asqueroso que acá hayan diez moscas y le hagan así [manoteo] y salgan volando y se tomen el jugo. Pero para un turista sí. Ellos conocen las medidas para controlar la mosca, pero no las aplican. (Entrevista a funcionario, 2013, agosto 31)

Por lo tanto, para algunos funcionarios el problema de esta cooperativa se presentaba porque los campesinos tenian una serie de creencias que no respondian a los cánones normativos exigidos dentro de la industria del turismo. Además, los campesinos tampoco materializaron los saberes administrativos, contables y de 
gestión empresarial. Desde la perspectiva de los saberes expertos, la cooperativa, como una organización de carácter empresarial y privado, necesitaba un manejo administrativo efectivo para su óptimo funcionamiento. Era central que los campesinos tuvieran una contabilidad, cuadernos de registros financieros, planes de mercadeo, estrategias para la consecución de metas a corto y largo plazo, etc. No obstante, nada de esto se ejecutó, y desde el punto de vista empresarial la cooperativa estaba destinada a fracasar. Un funcionario se quejaba:

Ellos tienen su empresa, pero no tienen un manejo administrativo competente. En donde no hay un manejo administrativo, donde vos no tienes una contabilidad, donde vos no tienes un registro de lo que se están poniendo, de lo que se está entregando, de lo que se está recibiendo, "mierda" eso no sirve para nada. Si vos no tienes un cuerpo administrativo que te responda por los movimientos económicos no hay nada. (Entrevista a funcionario, 2013, agosto 31)

Desde esta perspectiva, la empresarialización, como una de las justificaciones centrales que constituye la racionalidad neoliberal, incluso para concretar la privatización, no operó en las prácticas cotidianas de los campesinos. No responder a los principios empresariales significaba condenar a la cooperativa al fracaso. Incluso, algunas instituciones gubernamentales dejaron de apoyar y promocionar la iniciativa, porque no respondía a estándares empresariales y de calidad que hicieran posible su óptima gestión, y porque en últimas podría afectar los proyectos de desarrollo del departamento.

Por otra parte, los campesinos también rechazaron alianzas y procesos de privatización con empresas más grandes que fueron impulsadas por algunos funcionarios del gobierno regional. Varias empresas se interesaron en negociar con la iniciativa ecoturística por el potencial escénico de su ubicación y la facilidad de acceso para el avistamiento de aves, insectos y gran diversidad de flora y fauna. La propuesta más representativa surgió con una de las empresas más prestigiosas de turismo en el país. Esta empresa llegó al 
departamento del Guaviare interesada en vincular diferentes iniciativas de ecoturismo en su paquete de turismo de naturaleza.

Hubo varias reuniones en las que participaron miembros de la comunidad, de la empresa y funcionarios de distintas instituciones. Esta empresa privada les ofrecía a los campesinos arrendar la iniciativa ecoturística por diez años. La empresa se encargaría de proveer la infraestructura, el manejo administrativo, la promoción publicitaria, el mercadeo y la gestión general de la iniciativa ecoturística, mientras que los campesinos tendrían que trabajar para ella proveyendo los servicios de alimentación, guianza, transporte, etc. Para algunos de los miembros de la zona, la propuesta representaba una oportunidad para sacar adelante la iniciativa, aprovechando la experiencia que tenía la empresa privada en el sector: "algunos de nosotros pensamos que era mejor que viniera alguien y nos organice y nos ponga a trabajar" (Entrevista a campesino, 2013, septiembre 5). Otros, por el contrario, estaban convencidos de que una alianza de ese tipo conllevaría, más que a un bienestar, a una dependencia y a una generalizada explotación con pocos beneficios económicos, y que incluso entrañaría la probabilidad de perder no solo la iniciativa sino también sus fincas:

Era prácticamente principiar a ser empleados de ellos, y después, ¿quién los saca? Eso hasta de pronto terminamos perdiendo los terrenos. Mire por ejemplo lo de allá del Tayrona. La gente empezó a trabajar para una empresa que fue comprando pedacitos por ahí regados hasta que fueron sacando a la gente y ahora eso es privado. (Diario de campo, 2013)

Los campesinos conocian varios casos de empresas que habian negociado con otras comunidades de distintas regiones del país, gracias a los viajes que habian realizado años atrás junto a las instituciones. ${ }^{21}$ Así, los campesinos rechazaron las propuestas de

${ }^{21}$ Los trabajos de Ojeda (2012a, 2012b, 2016) examinan cómo la implementación del ecoturismo en el Parque Tayrona resulta en paisajes de despojo que no solo tienen que ver con el paramilitarismo, sino con las negociaciones cotidianas que se dan por el uso de los recursos. Los campesinos y prestadores de servicios turísticos asocian el deterioro de sus modos de vida y la alteración de sus condiciones laborales con la concesión de turismo que se le dio a Aviatur desde 2005. Ojeda (2012a, 2016) muestra que desde la concesión se han modificado los acuerdos socioespaciales que rigen la vida cotidiana de quienes viven y trabajan en el Parque. 
asociación con la empresa, señalando que "esas empresas vienen, se enriquecen y lo más probable es que nosotros salgamos perdiendo. Ellas pueden decir 'camine al Guaviare que es un potencial del turismo' y montar su cuento y nosotros quedar por fuera. Entonces nosotros dijimos que no" (Entrevista a campesino, 2013, septiembre 5).

Los funcionarios de las instituciones consideraron que el rechazo a la alianza con esta prestigiosa empresa había sido un error y una falta de visión para el desarrollo, no solo del ecoturismo, sino también del departamento:

Si uno no se les pega a las grandes empresas las cosas son muy jodidas. Si en el Guaviare no hay mayoristas ni inversionistas, entonces hay que ver a los grandes. Para que puedan funcionar este tipo de proyectos es necesario que pertenezcan a la red; con el turismo eso funciona es así, si uno no entra a jugar en sus redes nunca lograran ser funcionales. (Diario de campo, 2013)

Este testimonio demuestra dos cosas: 1) que algunas instituciones promovian la privatización de la iniciativa, suceso que responde a lo que algunos autores llaman la re-regulación del mercado amigable (Harvey, 2004, 2007; Duffy, 2008; Castree, 2008, 2011), en el que las instituciones gubernamentales y sus funcionarios, desde una perspectiva neoliberal, fomentan la privatización y la mercantilización para la acumulación de capital a través de distintos mecanismos; y 2) que las redes en las que participan poderosos grupos económicos son las que hacen posible el funcionamiento del ecoturismo, y, paralelamente, las que fomentan la expansión de las dinámicas neoliberales; sin ellas es improbable que esta actividad económico-ambiental prevalezca en el tiempo (Duffy, 2008). El ecoturismo es funcional solo si las iniciativas son controladas y gestionadas por grandes empresas privadas, o en su defecto, por organizaciones con sujetos capaces de autorregularse dentro de las lógicas establecidas por el mercado. 
La premisa de la racionalidad neoliberal en la que se supone que los campesinos debían adquirir técnicas de autoconducción empresarial y medioambiental para constituir una "cultura del emprendimiento" (Foucault, 2007; Li, 2007) no fue efectiva ni funcional. Esta incapacidad de los campesinos para autogestionarse en el marco de unos conocimientos ambientales y empresariales concretos condujo a que varios funcionarios públicos les atribuyeran a los campesinos la culpa de que algunas de las iniciativas ecoturísticas no funcionaran eficientemente. Esta situación responde a lo que Harvey (2007) llama la falta de fuerza competitiva: "si las condiciones de vida entre las clases más bajas de la sociedad se deterioran, esto se debe a su incapacidad, en general debida a razones personales y culturales, para aumentar su capital humano" (Harvey, 2007, p. 164). El simple hecho de no responder a esas premisas en las que efectivamente funciona el ecoturismo, como ser sujetos emprendedores con representaciones particulares de la Naturaleza, devino en el desmoronamiento paulatino de algunas de las iniciativas y en que varias instituciones dejaran de apoyarlas en su desarrollo. Además, justificó intentos de despojo en nombre de la conservación, de manera similar a lo que Dianne Rocheleau (2016) ha encontrado en Chiapas (México), a través de procesos de "despojo por deslegitimación” y lo que ha analizado Jennifer Devine (2014) en el caso de Petén, en Guatemala. El hecho de que los campesinos fuesen incapaces de llevar a cabo una óptima gestión del ecoturismo, legitimó la idea de que debían salir de ese mercado para darles paso a emprendedores capaces de reproducir el capital, como ocurrió con la prestigiosa empresa de turismo. Desde luego, esto promovió estrategias de despojo en el nombre de la conservación, principalmente, porque desde las racionalidades del ecoturismo los campesinos estaban impidiendo el desarrollo de la región como destino ecoturístico. Además, a algunos funcionarios públicos les interesaba que los campesinos dieran un paso atrás en la gestión del ecoturismo, para que sujetos "verdaderamente emprendedores" pudiesen abrir espacios de generación de capital de los que podrian obtener beneficios. Para los campesinos, esto podría implicar no solo la pérdida del manejo de las iniciativas ecoturísticas, sino también un impedimento para el acceso y uso de sus territorios. 
Así, la responsabilidad de la desposesión recayó sobre aquellos individuos que no pudieron ser empresarios de sí mismos, acto que se legitimaba porque desde la perspectiva neoliberal se considera moralmente correcto que todos los ámbitos de la sociedad sean mercantilizados, privatizados y empresarializados (Harvey, 2004). En otras palabras, la culpabilización de los campesinos en el fracaso de algunas de las iniciativas ecoturísticas escondió estrategias de acumulación por desposesión para beneficiar intereses particulares. ${ }^{22}$ Como lo plantea Fassin, "[...] la permanencia de una forma de culturalismo pragmático que hace de la cultura esencializada una interpretación cómoda de la realidad a la cual se confronta" (2005, p. 26) enmascara una realidad más cruda que es necesario leer y analizar desde la economía política. ${ }^{23}$

${ }^{22}$ Es preciso anotar que en el Guaviare se han manifestado procesos de despojo, a través de una selectiva aplicación de la normatividad ambiental sobre pequeños propietarios de tierras ubicados en zonas estratégicas para la acumulación de capital. Los campesinos de diversos lugares del departamento deben responder ante una legislación ambiental que rige sobre sus territorios. No adecuar la tierra y tampoco utilizar modos de producción sostenibles, obliga a las instituciones a actuar sobre los campesinos con castigos y sanciones que podrían ir desde la imposición de multas hasta la impugnación de los títulos de propiedad sobre sus predios. Algunos campesinos señalaban que la legislación ambiental, soportada por un régimen científico ambiental, estaba siendo utilizada para satisfacer los intereses de grupos particulares, y que se aplica selectivamente para cansar a la gente y sacarla de sus territorios, con el fin de hacerse con ellos y sacar provecho económico. Incluso algunos campesinos han decidido vender sus tierras, para alejarse del agobio de las autoridades ambientales.

23 Algunos procesos de despojo, legitimados por la incapacidad de los campesinos para autorregularse y responder a las lógicas de mercado, también se articularon de manera heterogénea a unas circunstancias sociohistóricas asociadas al conflicto armado, en el marco de la influencia del proyecto paramilitar sobre la institucionalidad. Castree (2008, 2011) indica que el proyecto neoliberal no es monolítico, sino que tiene efectos locacionales de acuerdo a los contextos donde sus políticas son aplicadas. A finales de la década de 1990, los paramilitares en Colombia adquirieron un gran poder al intensificar su presencia en diferentes regiones, a través de la ocupación del territorio a sangre y fuego y del uso de mecanismos violentos de intimidación, como masacres selectivas, terror, asesinatos y despojos (Rivera, 2007). Además, el proyecto paramilitar no solo estaba enfocado en la salvación del país del "demonio guerrillero", pues también tenía una marcada intención política: buscar una negociación con el Estado y conseguir un lugar legítimo en el poder (González, 2007; Romero, 2007; Valencia, 2007; CNAI, 2008). En ese contexto, fueron varios los funcionarios públicos que terminaron involucrados voluntaria o forzosamente con los paramilitares en distintas regiones de Colombia. Facciones de las élites regionales, como hacendados, grandes empresarios rurales, comerciantes, transportadores, políticos locales e, incluso, empresas petroleras, interactuaron con los paramilitares, quienes ofrecían sus servicios de protección y reclamaban apoyo. De esta manera, se estableció un fluido intercambio de servicios y relaciones entre los paramilitares y la sociedad. En efecto, la implementación de programas de conservación no estuvo ajena a estas dinámicas, en las que las extorciones y amenazas tuvieron un rol recurrente para la acumulación de capital. En otros trabajos (Montenegro-Perini, 2016), sugiero que la adaptación y las redefiniciones de las tecnologías de gobierno en el contexto guaviarense muestran que el enfoque de la gubernamentalidad neoliberal opera en la articulación de un gobierno biopolítico productivo, junto con poderes coercitivos del tipo soberano (Dean, 1999; Agamben, 2005; CastroGómez, 2010). Rose, contrario a lo que planteo, arguye que mientras "las vidas, las enfermedades y los problemas de muchos pueden ser ignorados o marginalizados en las economías políticas contemporáneas de la vida, dejar morir no es hacer morir - no hay un 'soberano' que planee la enfermedad o la muerte de los ciudadanos"' (Rose, 2007, p. 58). Pero, ¿qué pasa si consideramos los procesos violentos de desposesión en la era neoliberal? Estos procesos contradicen la afirmación de la medioambientalidad neoliberal como mero dispositivo biopolítico de hacer vivir, dejar morir. Aunque el gobierno neoliberal busque intervenir las poblaciones a través de poderes productivos del tipo de hacer vivir, también despliega tecnologías coercitivas del tipo de hacer morir, a través de la justificación de procesos de despojo violentos (Montenegro-Perini, 2016). 
Ante estos procesos de "despojo por deslegitimación" (Rocheleau, 2016), los campesinos reaccionaron reflexiva y activamente, mostrando nuevamente que la medioambientalidad neoliberal tiene unos límites que se producen en las interacciones entre las políticas y las dinámicas sociohistóricas de los lugares en donde se aplican (Ulloa, 2005; Li, 2007; Cepek, 2011). Uno de los campesinos comentaba:

El ecoturismo es una salida y estoy convencido. El único producto que no nos pueden "chibiar" ${ }^{4}$ es la parte natural que tenemos nosotros. A nosotros nos han ofrecido muchas veces negocios, empresas de Barranquilla, Medellín y Bogotá, pero nosotros somos conscientes de que debemos trabajar por nuestra cuenta y no dejar que nos quiten nuestras cosas. Es que los proyectos verdes del estado están dirigidos a los más ricos. Los proyectos ecoturísticos apoyados por el estado tenían y guardaban unos intereses capitalistas y nosotros no cuadrábamos sino como trabajadores de los más ricos. Entonces debemos hacer las cosas por nuestra cuenta, porque podríamos terminar siendo manejados por ellos o despojados de nuestras propias tierras. Y es que todo esto que usted ve es nuestra vida, no podemos perderlo. (Diario de campo, 2013)

Como es evidente en este testimonio, varios campesinos han tratado de seguir proveyendo servicios ecoturísticos, pero al margen de la interacción con el estado regional, o por lo menos, con cierta precaución en el momento de negociación con las instituciones. Varios campesinos han optado por crear redes de actores que trasciendan el ámbito local, para, de esta manera, evitar los intentos de despojo en nombre de la conservación. De hecho, han tratado de utilizar el ecoturismo resignificando sus prácticas y racionalidades como un espacio de resistencia a las dinámicas de privatización y mercantilización de sus territorios. Aunque no profundizaré sobre las modalidades de agencia en este artículo, sí quiero señalar que el rechazo de los campesinos a las privatizaciones se debió a un proceso reflexivo que establecieron en contra de las racionalidades de gobierno, originado en las interacciones entre el ecoturismo

\footnotetext{
${ }^{24}$ Este término es sinónimo de quitar en este contexto.
} 
y las formas de existencia de los campesinos (Montenegro-Perini, 2016). Como lo he mostrado en otros trabajos, "la implementación del ecoturismo neoliberal, que implicó la transformación de las subjetividades y naturalezas campesinas, resultó generando una efervescencia política a través de la cual los campesinos resistieron a los procesos de neoliberalización y estrategias de despojo" (Montenegro-Perini, 2016, p. 59).

\section{Despojos político-ontológicos}

La configuración de los procesos de despojo no responde únicamente a la pérdida de la tierra o de algún objeto material, sino a la suspensión y alteración de las relaciones socioecológicas de diversos actores, incluidos humanos y no-humanos. Además de los procesos de despojo que se legitiman en la culpabilización de los campesinos por su condición de sujetos incapaces de establecer acciones autorreguladoras y emprendedoras bajo las lógicas del mercado, el ecoturismo en el Guaviare ha desplegado otros tipos de intentos de despojo que yo he llamado despojos político-ontológicos. Las percepciones de la naturaleza que subyacen en las políticas ambientales responden a unas ideas racionales asociadas con la modernidad y el neoliberalismo. Descola (2012) y Blaser (2009a, 2009b, 2013) señalan que existe una multiplicidad de maneras de distribuir y establecer qué es lo que existe. Para ellos la ontología moderna, que hace una división tajante entre sociedad-naturaleza, es una formación ontológica entre otras. Cuando la ontología moderna con sus formas de gobernanza invoca a la Naturaleza como un principio trascendental y universal, esconde las multiplicidades, heterogeneidades e inconsistencias de las dinámicas socioecológicas de disímiles grupos humanos y no-humanos (Swyngedouw, 2010). Este tipo particular de comprensión de la Naturaleza implica un intento de solucionar el sentido caótico y complejo de las diversas naturalezas y sus relaciones co-constitutivas con las sociedades (Swyngedouw, 2011). Esto eclipsa el momento político en el proceso 
de darles significado a las naturalezas, despolitizándolas y convirtiéndolas en un objeto social y políticamente neutro.

Los campesinos del departamento del Guaviare, así como poblaciones de otras regiones como la Macarena (Ruiz, 2010, 2013), le dan intencionalidad a los animales, los ríos, las lagunas, el clima y la selva (Vélez, 2015), convirtiéndolos en seres sensibles cuya existencia material condiciona sus modos de vida. De la misma manera como De la Cadena (2010) lo señala para el caso de las comunidades andinas en el Perú, las prácticas con los territorios y los animales permiten el afecto y respeto necesarios para mantener la condición relacional entre humanos y no-humanos, que hacen parte fundamental de la vida de los campesinos en la Amazonia. El territorio que habitan no es un simple espacio para la producción agrícola; es un escenario en donde se establecen complejas relaciones simbólico-materiales que configuran formas particulares de existencia, que se podrian considerar como formaciones ontológicas que difieren de aquella que divide la sociedad de la naturaleza (ontología moderna). ${ }^{25}$ Es decir, las relaciones simbólico-materiales que se establecen entre humanos y no-humanos deberían ser escuchadas por las realidades que revelan, en vez de ser concebidas como meras creencias culturales que hacen una interpretación relativa de la Naturaleza (Ingold, 2000). Esto implica concebir la producción de realidad como un continuo ensamblaje de relaciones simbólico-materiales que tienen efectos performativos, cambiantes e inestables entre los seres que la componen (Latour, 1993). Como lo ilustra Blaser, "la realidad que está siendo postulada aquí se distancia de la división cultura/naturaleza para arribar a la formulación simbólico-material" (2013, p. 23).

Pero es precisamente este entramado de relaciones socioecológicas lo que las tecnologías de gobierno neoliberales niegan e invisibilizan. Las relaciones simbólico-materiales que tienen los

\footnotetext{
${ }^{25}$ Lo que los campesinos establecen con la selva no es necesariamente equivalente a lo que las tecnologías de gobierno neoliberales llaman Naturaleza. Sin embargo, esto no quiere decir que las formas de distribuir qué es lo que existe para los campesinos estén disociadas de las dinámicas del capitalismo moderno, ni autocontenidas en ellas. Por el contrario, las ontologías campesinas se reproducen y reconfiguran a través de las constantes tensiones entre sus relaciones socioecológicas más cotidianas y las del capitalismo.
} 
campesinos con la selva se invisibilizan o se conciben como meras representaciones culturales que deben ser modificadas a través del conocimiento propuesto por las politicas ambientales, para que los campesinos puedan jugar en las lógicas del capital. Los procesos de subjetivación en el marco de los discursos ambientales, que implican formas particulares de percepción de la Naturaleza y que son centrales para que los campesinos sean aceptados dentro de las dinámicas del ecoturismo neoliberal, configuran un escenario de negación de las relaciones socioecológicas que los campesinos establecen con sus territorios. Esta negación implica la imposibilidad de la emergencia de lo político a través de la visibilización de los múltiples mundos que podrían dinamizar alternativas al capitalismo moderno. Por lo tanto, el despojo no es necesariamente un proceso de desposesión de tierras o de los medios de producción (Marx, 1990) para crear las condiciones de continuidad del capitalismo, sino uno de despolitización y negación de otras ontologías que hacen del capitalismo un sistema con tecnologias de gobierno sutiles y muy poderosas (Montenegro-Perini, 2016).

En otros trabajos he examinado dos niveles de los despojos político-ontológicos (Montenegro-Perini, 2016). El primero tiene que ver con la negación de las formaciones ontológicas campesinas. En términos generales, la negación se da cuando las políticas ambientales y los funcionarios que las aplican desconocen las relaciones simbólico-materiales de los campesinos con la selva y reivindican la transformación de los modos de vida de los campesinos - considerados ilegales y depredadores del medioambiente- a través de la "cultura de la conservación". Un funcionario comentaba al respecto: "los campesinos están destruyendo la naturaleza con la coca y sus prácticas tradicionales. Ellos necesitan adquirir la cultura de la conservación" (Entrevista a funcionario, 2013, agosto 27). Otro funcionario, por su parte, señalaba: "Debe pasar mucho tiempo para que la gente modifique sus patrones culturales y que empiece a entender, que, si nosotros queremos que el departamento sea un destino turístico, ellos deben cambiar sus patrones culturales" (Entrevista a funcionario, 2013, agosto 31). Desde esta perspectiva, las racionalidades de gobierno representan las ontologías 
campesinas como meras expresiones culturales irracionales que deben ser transformadas mediante un proceso de medioambientalización y empresarialización para el buen funcionamiento del mercado. Ahora bien, en algunas ocasiones ciertas concepciones campesinas sobre la naturaleza son toleradas por la racionalidad de gobierno, siempre y cuando fomenten la generación de réditos económicos. El ecoturismo no solo se enfoca en resaltar la Naturaleza prístina del Amazonas, sino también ciertas formas culturales que pueden ser manejadas para dinamizar el mercado turístico. Las historias de la llegada de los campesinos al Guaviare, las formas de cultivar, pescar y convivir con el ecosistema son resaltadas como visos centrales para la promoción y experiencia del ecoturismo en la región. Algunos campesinos involucrados en el ecoturismo usan algunas de sus formas de relacionamiento con sus territorios para potenciar esta actividad económica: "es que los turistas no solo vienen a ver la Naturaleza sino también las cosas que hacemos nosotros; cómo cultivamos, cómo cazamos, cómo cuidamos la naturaleza, a qué horas salimos a pescar y a escuchar muchas de las historias que nosotros hemos tenido que vivir desde que llegamos al Guaviare" (Diario de campo, 2015). El problema no es que el campesino comparta parte de sus relaciones socioecológicas a potenciales turistas, sino que lo que se podria comprender como un escenario de visibilización de otras voces y mundos para la disputa de las coordenadas socioecológicas actuales, se reduce a una expresión cultural que responde al imperativo de la ontología moderna, que se gerencia con fines de acumulación de capital. Formaciones ontológicas disímiles son expulsadas del ámbito propiamente político al desplazarlas hacia el terreno de lo gerenciable y reducidas a expresiones culturales para ser mercantilizadas por las racionalidades y tecnologías del ecoturismo.

El segundo nivel se materializa en algunos de los alcances desestabilizadores que generan las tecnologías de gobierno sobre los modos de existencia de los campesinos. Si bien las racionalidades neoliberales de gobierno no se materializaron efectivamente en las prácticas campesinas con el ecoturismo, sí configuraron ciertos efectos desestabilizadores en sus formas de existencia. Por ejemplo, 
las relaciones de reciprocidad y vínculos afectivos de algunos campesinos con la selva fueron alterados. Los lazos de reciprocidad entre los vecinos han tenido un papel central en la subsistencia de los campesinos en la Amazonia. Si no fuera por ellos hubiese sido muy complicado establecerse en el agreste ecosistema amazónico. No obstante, la interacción con las instituciones y los intentos por poner a funcionar las iniciativas ecoturísticas generaron conflictos entre sus miembros. Algunos de ellos señalan que las rupturas de los lazos de reciprocidad se deben en gran parte a la implementación del tipo de ecoturismo promovido por el estado. Un campesino anotaba: "Aunque el ecoturismo nos ha ayudado a varios, también ha generado problemas. Nosotros antes nos ayudábamos todos con todos, pero ahora mucha gente ya no se habla. Así es muy jodido vivir en el monte" (Diario de campo, 2013). De acuerdo con este campesino, la ruptura de las relaciones de reciprocidad entre vecinos puede ser potencialmente riesgosa para las formas de interacción que ellos mantienen con la selva. Cuando los campesinos son incapaces de cooperar entre ellos es más difícil responder ante las pautas de comportamiento que se establecen con las entidades no-humanas, y, por lo tanto, es más complicado vivir en la selva. Otro ámbito de desestabilización se presenta en las relaciones de género y con el entorno. El PFGB llevó a cabo capacitaciones en donde el componente de género tenía un papel importante para fomentar beneficios igualitarios entre hombres y mujeres. Sin embargo, en la práctica la intervención institucional configuró roles de género distintivos, propios del capitalismo moderno, que tiene como base fundacional las oposiciones dualistas de la ontología moderna. Algunas campesinas señalaban: "Ahora yo tengo que trabajar más duro que antes, porque además de cocinar para los visitantes, tender las camas y limpiar las cabañas, tengo que cuidar a los hijos y alimentar a los pollos y demás animales. Mientras tanto el sinvergüenza de mi esposo se va a tomar unas cervezas con los turistas y a contar historias" (Diario de campo, 2013). En algunas circunstancias, la situación ha agobiado a las mujeres hasta el punto de que algunas han llegado a desplazarse al centro urbano, dejando sus tierras atrás, para trabajar como limpiadoras, vendedoras o amas de casa. Esto tiene consecuencias en las relaciones que ellas 
mantienen con su entorno, al introducirlas en otras dinámicas socioeconómicas, lejos de las labores del campo y de sus territorios (Montenegro-Perini, 2016).

La negación y desestabilización de las formaciones ontológicas campesinas son mecanismos de desposesión sofisticados de las tecnologías de gobierno neoliberales, ya que tratan de producir ciertas subjetividades y naturalezas favorables al sistema capitalista. Lo que trata de hacer el neoliberalismo es que los sujetos sociales dejen de operar en sus propias coordenadas socioecológicas para hacerlo en las que el sistema provee y promueve. Ahora bien, los despojos político-ontológicos no son completamente satisfactorios. Si bien el capitalismo moderno busca invisibilizar otros mundos para la reproducción de capital, tratando de vaciar la posibilidad de lo político para la creación de alternativas al sistema efectivas, en la interacción con poblaciones disímiles se establecen ensamblajes ontológicos (Montenegro-Perini, 2016) que reconfiguran constantemente las subjetividades (Butler y Athanasiou, 2013), naturalezas y coordenadas socioecológicas que resultan en distintas modalidades de agencia. Aunque el objetivo de este artículo no es profundizar en estos ensamblajes ontológicos (ver Montenegro-Perini, 2016), sí quiero dejar en claro que los campesinos operan desde la formación ontológica de la modernidad, presente en las políticas ambientales neoliberales (ecoturismo), y desde sus propias formas de existencia. Pero la interacción entre las dos no es de mera coexistencia, como si fueran independientes la una de la otra; por el contrario, las relaciones simbólico-materiales de los campesinos con la selva y los procesos de neoliberalización interactúan densamente constituyendo ensamblajes ontológicos difusos. No es ni una ni otra, son ninguna y ambas a la vez (ver Montenegro-Perini, 2016). De ahí que los campesinos vieran en el ecoturismo un escenario para la transformación de sus representaciones como ilegales y depredadores, así como también un espacio para legitimarse ante el gobierno y establecer mecanismos de resistencia en contra de los procesos de privatización y neoliberalización de la naturaleza antes descritos. 


\section{Conclusiones}

Recientemente, el ecoturismo se ha empezado a concebir como una actividad beneficiosa para las regiones sumidas en el conflicto armado, bajo el supuesto de que fomentaría espacios de apreciación de naturalezas prístinas y de aspectos culturales exóticos que promoverían el desarrollo sostenible. Un apartado de un periódico colombiano así lo muestra: "Si el acuerdo por la paz entre el Gobierno y las Farc llega a feliz término, el [eco] turismo será uno de los sectores claves para el desarrollo del país, de las regiones y sus comunidades, y para los desvinculados actores del conflicto. [...] Oportunidad para que el país muestre su naturaleza, playas, cultura y el carisma de la gente (Victoria, 2015). Sin embargo, el caso de la región de estudio en el Guaviare ilustra que el ecoturismo se puede comprender de manera más compleja en sus aciertos y limitaciones cuando se le analiza en contexto. Las iniciativas de ecoturismo pueden planearse en términos técnicos y de política pública para cumplir un efecto determinado, pero en su materialización contextual pueden generar otros resultados. No debemos dar por sentado que el ecoturismo garantiza el mejoramiento de las condiciones de vida de las poblaciones, porque en muchas ocasiones podría tener efectos contrarios -incluso perversos- a lo que busca. La difusa frontera entre capitalismo y conservación hace del ecoturismo un escenario poderoso de acumulación de capital que inevitablemente conlleva a sofisticados procesos de despojo en nombre de la conservación. Por un lado, al no responder ante las premisas de emprendimiento y capacidad de autorregulación de las racionalidades de gobierno neoliberales, los campesinos fueron deslegitimados como sujetos capaces de llevar a cabo iniciativas ecoturísticas, lo que justificó la idea de que debían salir de ese mercado para darles paso a emprendedores con las habilidades de reproducir el capital. De esta manera, la responsabilidad del despojo recayó sobre los campesinos que no pudieron ser empresarios de sí mismos y reproducir los valores del mercado. Por otro lado, más allá de ser solo un fenómeno de pérdida de tierras o uno destructor, el despojo es un fenómeno de alteración de las relaciones socioecológicas y de los modos de vida de poblaciones diferentes, en donde se reconfiguran subjetividades, naturalezas y agencias. En este artículo, además de concebirlo como fenómeno de suspensión de relaciones socioecológicas, el despojo fue abordado como uno político-ontológico, ya 
que busca cooptar la posibilidad de la emergencia de lo político a través de la invisibilización de otros mundos. En la producción de la Naturaleza y de los campesinos emprendedores-ambientales para poner en marcha iniciativas ecoturísticas en el Guaviare, la medioambientalidad neoliberal trató de invisibilizar y desestabilizar las relaciones socioecológicas que los campesinos mantienen con su entorno, así como negar otras formaciones ontológicas, para abrir nuevos rounds de acumulación de capital de formas sutiles. En consecuencia, debemos ser reflexivos a la hora de pensar el ecoturismo como una alternativa; mientras no exista un cambio radical de las racionalidades de gobierno (neoliberales), ni el ecoturismo ni otro servicio ambiental podrán considerarse alternativas fehacientes para conservar, desarrollar economías locales y superar el conflicto armado. Creo que es momento de tomarse en serio, no solo la presencia de los no-humanos en la configuración de lo político, como lo plantea De La Cadena (2010), sino también la reproducción constante de los mundos que se disputan en la interacción entre el neoliberalismo y otras formaciones ontológicas, porque de ellos resultan diversas modalidades de agencia que podrian dar alternativas a las coordenadas socioecológicas en las cuales estamos inmersos (el capitalismo moderno).

\section{Bibliografia}

AcciónSocial, UNODC. (2007). Organizaciones que cambian vidas: Programa Familias Guardabosques y Programa Proyectos Productivos. Bogotá: Impresol ediciones.

Agamben, G. (2005). Force-of-law. En State of Exception (pp. 32-40). Chicago: The University of Chicago Press.

Agrawal, A. (2005). Environmentality: Technologies of Government and the Making of Subjects. Durham and London: Duke University Press.

Arias, J. y Caicedo, A. (2016). Aproximaciones al despojo desde Colombia. Revista Colombiana de Antropología, 7-15. 
Arias, J. y Caicedo, A. (2017). Etnografias e historias de despojo: una introducción. Revista Colombiana de Antropología, 7-22.

Biersack, A. (2006). Introduction: Remaining Political Ecology. Culture/ Power/History/ Nature. En A. Biersack y J. Greenberg (Eds.), Reimagining political ecology (pp. 3-42). Durham: Duke University Press.

Blaser, M. (2009a). Political Ontology. Cultural Studies without Cultures? Cultural Studies, 23(5), 873-896.

Blaser, M. (2009b). The Threat of the Yrmo: The Political Ontology of a Sustainable Hunting Program. American Anthropologist, 111(1), 10-20.

Blaser, M. (2013). Notes toward a political ontology of environmental conflicts. En L. Green (Ed.), Contested Ecologies: Dialogues in the South on Nature and Knowledge (pp. 13-27). Cape Town: HSRC Press.

Bocarejo, D. (2012). Emancipation or enclosement? The spatialization of difference and urban ethnic contestation in Colombia. Antipode, 44(3), 663-683.

Bocarejo, D. y Ojeda, D. (2016). Violence and Conservation: Beyond Unintended Consequences and Unfortunate Coincidences. Geoforum 69, 176-183.

Bosa, B. (2016). ¿Despojados por ley? Los efectos del Decreto 68 de 1916 de la Gobernación del Magdalena sobre la población arhuaca. Revista Colombiana de Antropologia, 107-133.

Bourdieu, P. (1994). Espiritus de estado. Génesis y estructura del campo burocrático. Actes de la Recherche en Sciences Sociales, 96-97, 42-62.

Brockington, D., Duffy, R. e Igoe, J. (2008). Nature Unbound: Conservation, Capitalism and the Future of Protected Area. London: Earthscan.

Butler, J. y Athanasiou, A. (2013). Dispossession: The Performative in the Political. Cambridge: Polity Press. 
Caicedo, A. (2017). Vida campesina y modelo de desarrollo: configuraciones de despojo/privilegio en el norte del Cauca. Revista Colombiana de Antropología, 59-89.

Calle, L. (2017). Entre La Violencia, la colonización y la adjudicación de reservas. Relatos sikuanis sobre el abandono, el despojo y la recuperación del territorio. Revista Colombiana de Antropología, 91-122.

Camacho, J. (2017). Acumulación tóxica y despojo agroalimentario en La Mojana, Caribe colombiano. Revista Colombiana de Antropología, 123-150.

Cárdenas, R. (2012). Green Multiculturalism: Articulations of Ethnic and Environmental Politics in a Colombian 'Black Community'. Journal of Peasant Studies, 39(2), 309-333.

Castree, N. (2008). Neoliberalising nature: the logics of deregulation and reregulation. Environment and Planning A, 40, 131-152.

Castree, N. (2011). Neoliberalism and the biophysical environment 1: Putting Theory into Practice. Geography Compas, 4(12), 35-49.

Castro-Gómez, S. (2010). Historia de la gubernamentalidad: razón del estado, liberalismo y neoliberalismo en Michel Foucault. Bogotá: Siglo del Hombre Editores.

CNAI. (2008). Monografía Político Electoral, Departamento del Guaviare 1997 a 2007. Bogotá: Corporación Nuevo Arco Iris.

Cepek, M. (2011). Foucault in the Forest. Questioning Environmentality in Amazonia. American Ethnologist, 501-515.

De La Cadena, M. (2010). Indigenous cosmopolitics in the Andes: conceptual reflections beyond politics. Cultural Anthropology, 334-370.

Dean, M. (1999). Governmentality: Power and Rule in Modern Society. London: Sage Publications. 
Del Cairo, C. y Montenegro-Perini, I. (2015). Espacios, campesinos y subjetividades ambientales en el Guaviare. Memoria y Sociedad, 19(39), 49-71.

Del Cairo, C., Montenegro-Perini, I. y Velez, J. (2014). Naturalezas, subjetividades y politicas ambientales en el Noroccidente Amazónico: Reflexiones metodológicas para el análisis de conflictos socioambientales. Boletin de Antropología [Universidad de Antioquia], 29(48), 13-40.

Descola, P. (2012). Más alla de naturaleza y cultura. Buenos Aires: Amorrortu.

Devine, J. (2014). Counterinsurgency ecotourism in Guatemala's Maya Biosphere Reserve. Environ. Plann. D: Soc. Space, 32, 984-1001.

DNP. (2003). Plan Nacional de Desarrollo: Hacia un Estado comunitario. Bogotá: Imprenta Nacional de Colombia.

Duffy, R. (2008). Neoliberalising Nature: Global Networks and Ecotourism Development in Madagaskar. Journal of Sustainable Tourism, 16(3), 327-344.

Fassin, D. (2005). Faire de la santé publique. Rennes: Editions de 1'Ecole nationale de santé publique.

Federici, S. (2010). Calibán y la bruja. Mujeres, cuerpo y acumulación originaria. Madrid: Traficantes de Sueños.

Fletcher, R. (2010). Neoliberal Environmentality: Towards a Poststructuralist Political Ecology of the Conservation Debate. Conservation and Society, 8(3), 171-181.

Foucault, M. (1999). La gubernamentalidad. En M. Foucault, Obras esenciales. Volumen III: Estética, ética y hermenéutica (pp. 175-198). Barcelona: Paidós.

Foucault, M. (2007). Nacimiento de la Biopolitica: curso en el College de France (1978-1979). México y Buenos Aires: Fondo de Cultura Económica. 
Gershon, I. (2011). Neoliberal Agency. Current Anthropology, 52(4), 537-555.

González, C. (2014). El que tiene tierra, que la atienda (Tesis de pregrado). Departamento de Antropología, Universidad del Rosario, Bogotá.

González, J. J. (2007). Los paramilitares y el colapso estatal en Meta y Casanare. En M. Romero (Ed.), Parapolitica, la ruta de la expansión paramilitar y los acuerdos politicos. Bogotá: Corporación Nuevo Arco Iris.

Harvey, D. (2001). The art of rent: globalization and the commodification of culture. En D. Harvey, Spaces of Capital: Towards a Critical Geography (pp. 394-411). New York: Routledge.

Harvey, D. (2004). The 'New' Imperialism: Accumulation by Dispossession. Socialist Register, 40, 63-87.

Harvey, D. (2007). Breve historia del neoliberalismo. Oxford: AKAL.

Ingold, T. (2000). Hunting and gathering as ways of perceiving the environment. En T. Ingold, The perception of the environment: essays on livelihood, dwelling \& skill (pp. 40-60). New York: Routledge.

Latour, B. (1993). We Have Never Been Moderns. Cambridge: Harvard University Press.

León, A. (2017). Domesticando el despojo: palma africana, acaparamiento de tierras y género en el Bajo Aguán, Honduras. Revista Colombiana de Antropologia, 151-185.

Li, T. (2007). The Will to Improve: Governmentality, Development, and the Practice of Politics. Durham: Duke University Press.

Marx, K. (1990). Capital: A critique of Political Economy. Volume 1. Fourth. England: Penguin Books. 
Meertens, D. (2016). Entre el despojo y la restitución: reflexiones sobre género, justicia y retorno en la costa caribe colombiana. Revista Colombiana de Antropología, 45-71.

Montenegro-Perini, I. (2014). El ecoturismo en Juego: procesos de neoliberalización, tecnologias de gobierno y agencias campesinas en el Guaviare (Tesis de pregrado). Pontificia Universidad Javeriana, Bogotá.

Montenegro-Perini, I. (2016). Ecotourism, Peasants and The Rainforest: reconfigurations of peasants' subjectivities and natures, and processes of dispossession in the Northwest Colombian Amazonia (MA dissertation). University of Manchester, Manchester.

Morris, M. (2017). La cuestión de la tierra: el despojo y la posesión en el trabajo etnográfico. Revista Colombiana de Antropología, 27-57.

Ojeda, D. (2012a). Producing Paradise: The Violent Geographies of Tourism in Colombia (Ph.D. Dissertation). Clark University, Worcester, Massachusetts.

Ojeda, D. (2012b). Green pretexts: Ecotourism, neoliberal conservation and land grabbing in Tayrona National Natural Park, Colombia. Journal of Peasant Studies, 39(2), 357-375.

Ojeda, D. (2013). War and Tourism: The Banal Geographies of Security in Colombia's 'Retaking'. Geopolitics, 18(4), 759-778.

Ojeda, D. (2016). Los paisajes del despojo: propuestas para un análisis desde las reconfiguraciones socioespaciales. Revista Colombiana de Antropología, 19-43.

Ortiz, D. (2016). Las politicas de desarrollo alternativo en el Guaviare: formación local del estado y producción estatal del espacio (Trabajo de grado). Pontificia Universidad Javeriana, Bogotá.

Rivera, E. d. (2007). History of the paramilitarismo in Colombia. Historia (Sao Paulo), 26(1), 134-153. 
Rocheleau, D. (2016). Redes, raíces y territorios en acaparamiento verdes y resistencias. Alternativa Revista de Estudios Rurales, 44-83.

Romero, M. (2007). Nuevas guerras, paramilitares e ilegalidad: una trampa difícil de superar. En M. Romero (Ed.), Parapolitica, la ruta de la expansión paramilitar y los acuerdos político. Bogotá: Corporación Nuevo Arco Iris.

Rose, N. (1996). The death of the social? Re-figuring the territory of government. Economy and Society, 25(3), 327-356.

Rose, N. (2007). Politics and Life. En N. Rose (Ed.), The Politics of Life Itself: Biomedicine, Power, and Subjectivity in the Twenty-First Century (pp. 41-76). Princeton: Princeton University Press.

Ruiz, D. (2010). Las premisas de la selva: Representaciones de la naturaleza en una zona de colonización campesina. En M. Chaves y C. Del Cairo (Eds.), Perspectivas antropológicas sobre la Amazonia contemporánea (pp. 335-361). Bogotá: Instituto Colombiano.

Ruiz, D. (2013). Enchanted forests, entangled lives. Spirits, peasant economies and violence in Northwest Amazonia (MsC Dissertation). McGill University, Montreal.

Shore, C. (2010). La antropología y el estudio de la política pública: reflexiones sobre la formulación de las políticas. Antipoda, 10, 21-49.

Sinchi. (2006). Capacitación sobre servicios ambientales con base en el trabajo concertado de planificación, valoración y diseño de una experiencia piloto en ecoturismo, para los departamentos del norte amazónico colombiano. Guaviare: Documento sin publicar.

Swyngedouw, E. (2010). Apocalypse Forever? Post-political Populism and the Specter of Climate Change. Theory, Culture \& Society, 27(2-3), 1-20.

Swyngedouw, E. (2011). Nature does not exist! Sustainability as Symptom of a Depoliticized Planning. Urban, (1), 41-66. 
Ulloa, A. (2005). The Ecological Native: Indigenous Peoples' Movements and Ecogovernmentality in Colombia. New York: Routledge.

Valencia, L. (2007). Los caminos de la alianza entre paramilitares y políticos. En M. Romero (Ed.), Parapolitica, la ruta de la expansión paramilitar y los acuerdos politicos. Bogotá: Corporación Nuevo Arco Iris.

Vélez, J. (2015). Entre la selva y el estado: Politicas públicas, comunidades campesinas y prácticas cotidianas en la Amazonia noroccidental colombian (Tesis de pregrado). Pontificia Universidad Javeriana, Bogotá.

Vergara, T. (2016). Las lineas sobre la selva: un análisis antropológico del ordenamiento territorial en el Guaviare (Tesis de pregrado). Pontificia Universidad Javeriana, Bogotá.

Victoria, E. J. (2015, mayo 20). La paz: revancha para el turismo. El Tiempo. Recuperado de http://www.eltiempo.com/estilo-de-vida/viajar/turismocolombiano-en-el-postconflicto/ 15789376

West, P. (2008). Tourism as science and science as tourism. Environment, society, self and other Papua New Guinea. Current Anthropology, 49(4), 597-626.

West, P. y Carrier, J. (2004). Ecotourism and Authenticity: Getting away from it all? Current Anthropology, 45(4), 483-498.

Zorro, C. (2011). Políticas de desarrollo alternativo en Colombia (19822009). En A. Gaviria y D. Mejía (Eds.), Politicas antidroga en Colombia: éxitos fracasos y extravios (pp. 91-120). Bogotá: Universidad de los Andes.

\section{Cómo citar este artículo}

Montenegro-Perini, I. (2017). Ecoturismo, gubernamentalidad neoliberal y despojos en la Amazonia colombiana. Universitas Humanística, 84, 35-73. https: / / doi.org/10.11144/Javeriana.uh84.egnd 